\title{
Donor preparation in descemet membrane endothelial keratoplasty
}

\author{
Prafulla K Maharana*, Pranita Sahay, Deepali Singhal, Namrata Sharma and Jeewan S Titiyal \\ Dr. Rajendra Prasad Centre for Ophthalmic Sciences, All India Institute of Ophthalmic Sciences, New Delhi, India
}

\begin{abstract}
Descemet membrane endothelial keratoplasty (DMEK) is currently the preferred endothelial keratoplasty technique. The major challenges in performing DMEK include donor cornea preparation and graft attachment. The availability of pre-stripped DMEK tissue in western countries may address the problem of donor preparation. However, in developing countries the lack of facility for the same is a major obstacle in the widespread use of this surgical technique. This review summarises the current available techniques of DMEK donor preparation in addition to a modified simple technique of DMEK roll preparation by the authors.
\end{abstract}

\section{Introduction}

Introduced by Melles in 2006, descemet membrane endothelial keratoplasty (DMEK) has gained increasing popularity and interest as a method for endothelial keratoplasty [1]. In this procedure the recipient's diseased descemet-endothelium is replaced with the donor's healthy descemet-endothelium complex. The major advantage of DMEK over other methods of endothelial keratoplasty is early visual rehabilitation with better visual outcomes, and a low risk of graft rejection [2-6]. The other less discussed but often the most important advantage from the perspective of developing countries is its cost-effectiveness. It does not require sophisticated instruments like microkeratome.

Despite these advantages, DMEK is not a widely practiced surgery. The major limitations are difficult graft preparation, increased surgical manipulation and higher rates of early postoperative graft detachment. In addition, a steep learning curve leading to wastage of good quality donor tissues is a major concern in developing countries which may be a reason for lesser preference of this surgical technique among corneal surgeons. Several techniqueshave been described in the past with use of certain specialized instrument such as Muraine punch, Barron vacuum block, artificial anterior chamber, curvilinear forceps with halfmoon shaped non-toothed anterior segment, Y-hook instrument, etc for donor tissue preparation [4-6].

\section{Relevant anatomy}

With the constant evolution in the field of keratoplasty there has been a shift by corneal surgeons from conventional full thickness penetrating keratoplasty to disease specific replacement of the corneal layers. Thereby a clear-cut understanding of the corneal anatomy is extremely pertinent for understanding of the various component corneal surgery. Cornea consists of the following layers from anterior to posterior - epithelium, bowman's membrane, stroma, descemet membrane and endothelium. Dua's layer is an acellular, predescemetic layer that separates the posterior stroma from the Descemet's membrane [7]. The DMEK graft consists of Descemet membrane (DM) and corneal endothelium. Therefore, average thickness of DMEK graft is graft thickness is 14-20 microns [8].
Schrehardt et al. [9] have described the ultrastructural and immunohistochemical details of the cleavage plane between Descemet's membrane (DM) and posterior corneal stroma. DM is the basement membrane of corneal endothelium consisting of both collagenous (type IV, VIII, XII, and XVIII) and noncollagenous components (fibronectin, laminin, vitronectin, perlecan, nidogen, dermatan sulfate, keratan sulfate, heparan sulfate, and chondroitin sulfate). It has an anterior banded (fetal) layer of approximately 3 microns and a posterior nonbanded (postnatal) layer of approximately 10 microns which gradually increases with age.

DM plays an important role in endothelial cell differentiation and proliferation. It has a unique mechanical property to resist both lateral and axial strain. Interfacial matrix is a narrow transitional zone of amorphous extracellular matrix that attaches the DM with endothelium. However this adhesion is not strong enough, thereby DM can be separated relatively easily from the adjacent stroma. This property is exploited during DMEK surgery in both the donor tissue and host bed preparation [9] (Table 1).

\section{Surgical technique and modification}

\section{Donor tissue selection}

Donor tissue selection is extremely important for DMEK surgery. It is recommended to use tissues with donor age $>55$ years for DMEK. Donor tissue with age $>65$ years peel faster than those $<65$ years. The deposition of posterior non-banded layer of the DM with increasing age is hypothesised to be responsible for this advantage seen in older donor tissues. Also, donor tissue with age $<50$ years form spontaneous tight scrolls which can lead to intraoperative difficulty in unscrolling of the DM scroll. Also, these tissues are associated with subsequent

${ }^{*}$ Correspondence to: Prafulla K Maharana, Asst. Professor, Department of Ophthalmology, Room 491, Dr. R. P. Centre for Ophthalmic Sciences, All India Institute of Medical Sciences, New Delhi 110049; Tel: +91-8800776957; E-mail: drpraful13@gmail.com

Received: February 11, 2019; Accepted: February 18, 2019; Published: February 20,2019 
Table 1. Success of DMEK tissue preparation with different techniques

\begin{tabular}{|c|c|c|c|c|c|c|}
\hline Author, year & Study type & Sample size & Technique & Success rate & Endothelial cell loss & Other complications \\
\hline Salvalaio G, 2014 & Experimental & 30 & SubHyS technique & $100 \%$ & $27.69 \%$ at 7 days & $\begin{array}{l}\text { Bubble burst in } 5 \text { cases } \\
\text { (excluded) }\end{array}$ \\
\hline Tenkman LR, 2014 & Experimental & 263 & SCUBA technique & $99 \%$ & & HST in $13 \%$ \\
\hline Rieck PM, & Experimental & & $\begin{array}{l}\text { Manual delamination } \\
\text { versus combined manual } \\
\text { delamination and } \\
\text { hydrodissection }\end{array}$ & $\begin{array}{c}\text { Failure rate } 25 \% \& 4.5 \% \\
\text { respectively }\end{array}$ & $6 \& 5.2 \%$ respectively & \\
\hline Tausif HN, 2014 & Experimental & 50 & $\begin{array}{l}\text { Forceps peeling } \\
\text { technique }\end{array}$ & $76 \%$ & $\begin{array}{c}\text { No diff } \mathrm{b} / \mathrm{w} \text { pre and post } \\
\text { preparation }\end{array}$ & $\begin{array}{c}\text { DM tears }(10 \%), \text { severe } \\
\text { cell loss }(14 \%)\end{array}$ \\
\hline Parekh M, 2014 & Experimental & 44 & $\begin{array}{l}\text { Submerged hydro- } \\
\text { separation }\end{array}$ & $100 \%$ & $11.48 \%$ post preparation & \\
\hline Lie JT, 2008 & Experimental & 7 & Manual peeling & & $4-7 \%$ & \\
\hline $\begin{array}{l}\text { Schlötzer- Schrehardt, } \\
2013\end{array}$ & $\begin{array}{l}\text { Prospective, single- } \\
\text { center, nonrandomized, } \\
\text { consecutive case series. }\end{array}$ & 350 & $\begin{array}{l}\text { Bimanual submerged } \\
\text { technique }\end{array}$ & $95.7 \%$ & & Isolated tears $(2.3 \%)$ \\
\hline Yoeruek E, 2013 & Experimental & 16 & $\begin{array}{c}\text { 1-point forceps dissection } \\
\text { vs. curvilinear forceps } \\
\text { dissection }\end{array}$ & $100 \%$ & $\begin{array}{l}7.2 \% \text { and } 3.4 \% \\
\text { respectively }\end{array}$ & \\
\hline
\end{tabular}

risk of post-operative detachment [10]. The endothelial cell density on specular microscopy should be $>2500$ cells $/ \mathrm{mm}^{2}$ [5]. Scleral rim is not a limiting factor for donor tissue selection for DMEK as in DSAEK.

\section{Partial thickness trephination}

The donor tissue is first placed on a teflon block with endothelium side up for DMEK scroll preparation. Some authors prefer to use a suction block ((Hanna trephination system; Moria SA, Antony, France) for better stability of the tissue during peeling [11]. This is followed by partial thickness trephination of the donor tissue from the endothelial side. The various trephines used for this step include hand held disposable trephine, Barron Vaccum Punch (Katena,Inc, Denville, N.J., USA), Murraine's punch and Moria DSAEK trephination system $[11,12]$. The size of trephine vary from 8 to $8.5 \mathrm{~mm}$.

\section{DM staining}

At this stage staining of the EDM complex is done with trypan blue (TB) for 60 seconds [11]. This aids in easy visualization of the endothelium-DM (EDM) complex as well as its edges that aids in better visualization during the subsequent steps of tissue preparation which is vital for a successful tissue harvesting. It also helps in better visualisation of the donor tissue when injected in the eye. Other dye used for this purpose is Brilliant Blue G (BBG 0.1\%, w/v) for 60 seconds. It is hypothesised that BBG is less toxic to the corneal endothelium than trypan blue. However, no significant difference was noted in the post-operative specular count in tissues stained with TB and BBG [13].

\section{DM Peeling}

After staining the donor tissue, the peripheral rim of EDM complex is peeled with the help of forceps. The most commonly performed technique for DM peeling is the manual peeling method described by Melles et al wherein the donor corneoscleral rim is immersed in Balanced Salt Solution (BSS) and the DM is peeled with 1-point fine non-toothed forceps $[1,14]$.

Giebel and Price described the SCUBA (submerged corneas using backgrounds away) technique, where the donor tissue is submerged in Optisol or BSS during tissue peeling to minimize the surface tension on the donor tissue allowing the DM to settle back onto the stroma. In this technique a MicroFinger (Moria) is used for 360-degree dissection and peeling of the periphery EDM complex from the underlying stroma at a $10 \mathrm{~mm}$ zone. The tissue is then peeled centrally approximately
0.5 to $1.0 \mathrm{~mm}$ from the edge. The DM is then grasped with fine nontoothed forceps and slowly stripped completely away from the stroma towards the centre while leaving the centre EDM complex attached to the underlying stroma [15].

Pulling the edge of EDM with single forceps can result in DM tearing and donor tissue loss. To reduce this problem bimanual technique of tissue harvesting with two forceps was described by Kruse et al. [11] and Schlotzer- Schrehardt et al [16]. For complete separation of the EDM complex from the underlying stroma, the margin of the EDM is grasped with one forceps at the 11-o'clock position and with the other forceps at 2-o'clock position. The EDM is pulled towards the centre by simultaneous movement of both the forceps. This results in separation of the first quadrant following which the suction block is rotated by 45 degrees and the EDM in the second quadrant is separated from the stroma in a similar fashion as described above. While separating the last quadrant, a small portion of EDM is left attached to the stroma to avoid a free floating EDM complex at this stage and subsequently allow for easy punching of the EDM complex [11,16].

Yoeruek et al. described the use of a curvilinear forceps with a halfmoon shape non- toothed that can equally distribute the forces needed for DM separation [17].

Pneumatic dissection of the donor tissue, initially described for anterior lamellar keratoplasty, has also been utilised for donor tissue preparation in DMEK. Venzano et al. [18] described the use of an artificial anterior chamber (AAC) to harvest the Descemetendothelium complex with the Anwar air-bubble technique [18]. They recommended staining of the endothelium with trypan blue for better visualization of the needle position and pressure reduction in the AAC just before air injection to facilitate successful formation of big bubble. They recommedded immediate deflation of the air bubble to avoid endothelial cell loss [18].

Zarei-Ghanavati et al. [19] used a reverse big-bubble technique for DMEK tissue preparation. In this technique a 27 -gauge needle attached to a $2 \mathrm{ml}$ syringe filled with air is inserted into the posterior stroma with the entry point located just outside of the Schwalbe line keeping the bevel of the needle up. The needle is then advanced to the centre of cornea followed by gentle air injection to create corneal emphysema. The needle is then removed, and the big bubble is collapsed from the scleral part of the corneoscleral rim by aspirating the air. High success rate was noted with older tissues with this technique [19]. 
This technique of pneumatic dissection was further modified by Busin et al. [20] wherein the donor tissue is mounted on AAC and superficial keratectomy is done with a 300 -micron microkeratome head prior to air injection. The donor tissue is subsequently placed over the teflon block with endothelium side up and air is injected into the residual donor tissue with a $30-\mathrm{G}$ needle into the peripheral cornea, $1 \mathrm{~mm}$ from the limbus. The "bubble" is allowed to expand as far as possible into the periphery [20].

Muraine et al. [12] reported a technique in which the cornea is mounted on an AAC with the endothelium side up and a $330^{\circ}$ superficial trephination is done with a trephination blade that is first broken to generate a fragment 3-4 mm long. The peripheral endothelium is detached with a spatula or jaws of a Troutman forceps on either side of the zone where Descemet membrane is attached. A cannula is then inserted beneath the flap through which BSS is injected with a 27 gauge cannula mounted on a syringe to detach the DM by hydrodissection [12]. The peeling of the EDM complex is reposited over the donor stromal bed, while leaving an attached area $2-3 \mathrm{~mm}$ broad to avoid a free floating graft at this stage.

\section{DM Marking}

After peeling of the host EDM complex, it is important to mark the EDM complex to ensure correct orientation of the donor tissue when injected into the eye. Misidentification of the graft orientation in the anterior chamber can lead to eventual primary graft failure. The stromal bed of the donor cornea is punched with a $2 \mathrm{~mm}$ punch. Following this the EDM complex is reposited over the stromal bed and the donor tissue is inverted with the epithelium side up. Through the 2 $\mathrm{mm}$ window the stromal side of the EDM complex is marked with a $\mathrm{S}$ stamp stained with gentian violet paint $[21,22]$.

The other technique described by Bachmann et al. consists of asymmetric marking on the edge of the graft using a 1-millimetrediameter dermatological biopsy punch at 3 sites at the edge of donor tissue from the endothelial side ( 2 close to one another and 1 with a recognizable distance) to ensure proper anterior posterior orientation of the donor tissue [23].

Bhogal et al. [24] described a Single triangular marking technique using a 30-degree incision knife for DM marking. Matsuzawa et al described the four asymmetric semicircular marking technique with 1.0- and 1.5-mm diameter dermatomal punch at the edge of the donor from endothelial side. The small and large marks are paired and the two pairs are placed at the opposite ends of the graft diameter [25].

\section{Donor punching}

After marking the donor tissue the EDM complex is punched with 7.5-8.0 $\mathrm{mm}$ trephine. The tissue is then carefully peeled avoiding peripheral rip off.

\section{Author's modification}

The author's follow a simple technique of Sinsky Hook Assisted Roll Preparation for DMEK (SHARP). (Figures 1 and 2) This technique is a simple, easy to learn, cost effective technique that can be performed with the help of few commonly used keratoplasty instruments. The technique is described below.

The corneoscleral rim is first placed on a Teflon block partially filled with tissue preservation media. An initial partial thickness trephination is done with a $9.5 \mathrm{~mm}$ manual trephine (Madhu trephines, India). At this step, it is essential not to apply undue

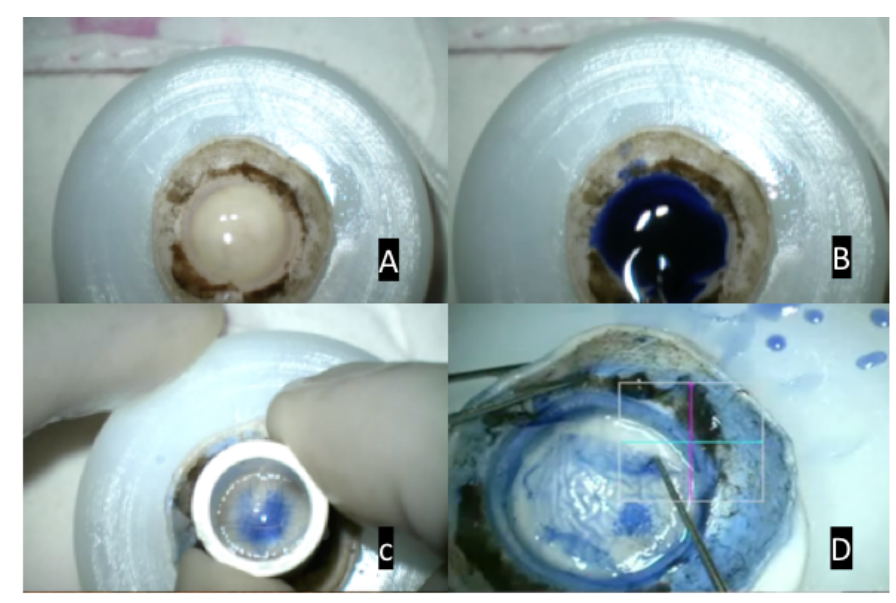

Figure 1. $A$ - Donor Corneal Tissue on Teflon block; $B$ - Staining of Descemet Membrane with $0.06 \%$ Trypan blue; $C$ - Partial trephination of donor tissue from the endothelial side using $9.5 \mathrm{~mm}$ trephine; $D$ - inside out movement of Sinsky hook to separate the descemet membrane from an underlying stroma

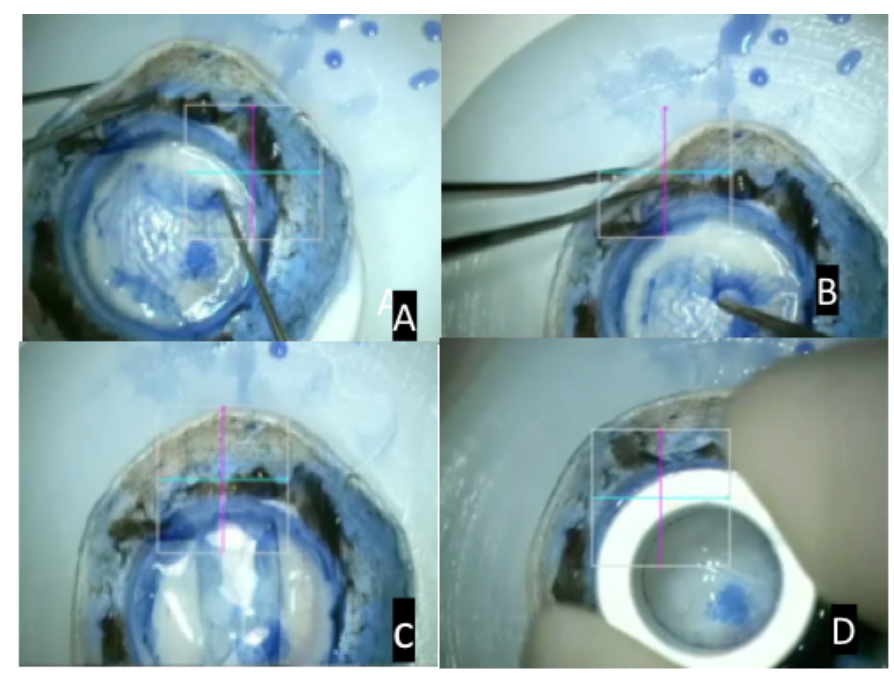

Figure 2. $A$ - Extending the plane of separation to about 3-5 mm towards center; $B$-technique of membrane peeling; $\mathrm{C}$ - repositioning of freed descemet roll; $D$ - Trephination of the descemet roll using $8 \mathrm{~mm}$ trephine

force in order to avoid a full thickness punching. A useful sign for adequate depth of trephination is a ring formation, observed within the inner edge of trephine during this step. A broad ring is seen in the case of deep punching of the tissue while a narrow ring suggests a superficial trephination (Figure 3). Alternatively, a guarded trephine can also be used as it would be both precise and safe. However, in our experience, manual trephine also works well, especially if the ring sign is appreciated carefully. The tissue is then stained with Trypan blue $0.06 \%$ for 3 minutes, followed by a gentle wash with tissue fluid. A 360-degree separation of the descemet-endothelium complex from the posterior stroma was obtained using a sinsky hook. (Figure 4) The separation plane extended $2 \mathrm{~mm}$ inside the edge of the partial thickness trephination. The angulation of sinsky hook with reference to the tissue plane was kept at around 30- 45 degree for best results. Inside out slicing movements were made with the sinsky hook for separating the descemet endothelium complex. While making this slicing movement, it is essential to apply pressure only at stroma rather than the descemet membrane (DM). In case, there is difficulty in separating the DM roll from the underlying stroma, the stroma can be held with limbs or plain forceps at the site of partial thickness trephination and 


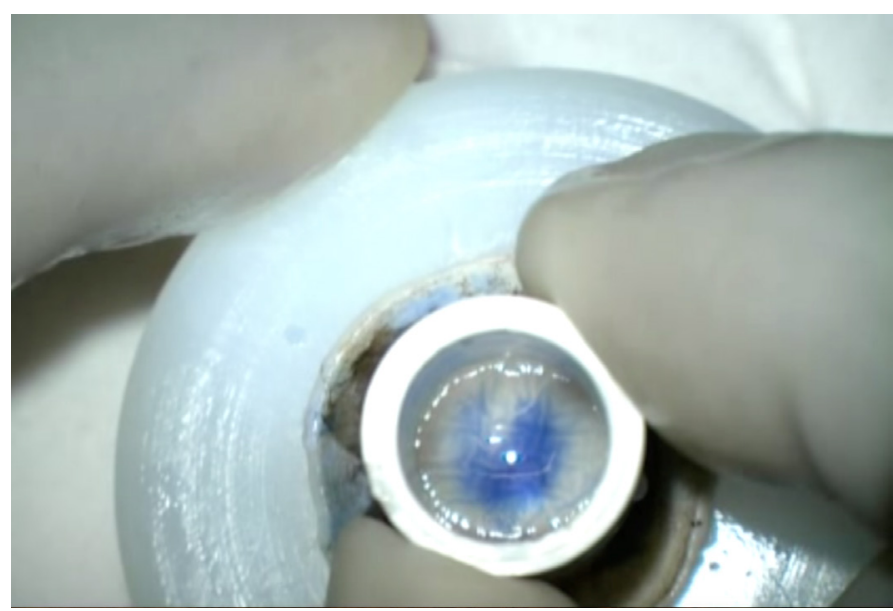

Figure 3. Ring sign giving an indirect guidance about the depth of trephination

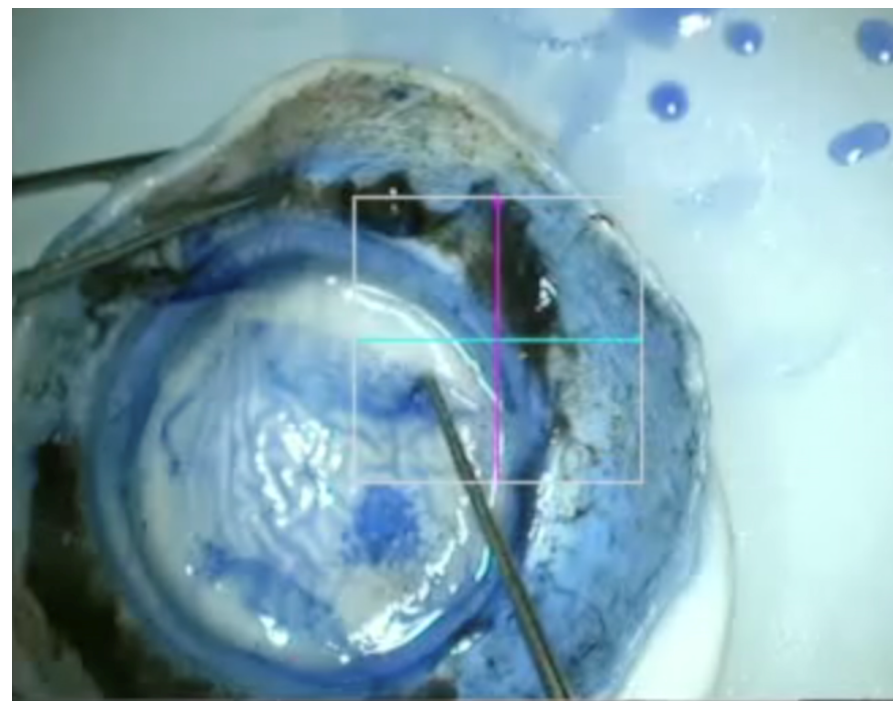

Figure 4. $2 \mathrm{~mm}$ of peripheral frill of descemet membrane separated using Sinsky hook

pulled outwards while proceeding with the sinsky assisted dissection of the descemet endothelium complex. This step makes the underlying tissue taut and the edge of DM roll more prominent leading to an ease in tissue dissection at the appropriate plane. Also, depressing the peripheral tissue (beyond the edge of partial thickness trephination) makes the edge of DM roll more prominent leading to ease in tissue dissection. After obtaining a 360-degree frill, the separation plane is further extended 3-4 $\mathrm{mm}$ from the edge to an extent of around 4-5 clock hours. This site is now placed diagonally opposite to the surgeon. The assistant supports the Teflon block and holds the tissue firmly with toothed forceps. At every step it is essential to have a good assistance for holding the corneoscleral button in position. Bimanual peeling of the descemet endothelium complex is initiated from the same site by holding the edge of the frill with two McPherson forceps 2 to 3 clock hours apart. Alternately a suture tying forceps can also be used. The tissue is then gently lifted up and pulled towards the surgeon leaving it attached for around 1-2 $\mathrm{mm}$ at the opposite end. The DM roll is then reposited back. The tissue is now trephined with an $8 \mathrm{~mm}$ trephine. At this step, it is essential to note that if there are any peripheral micro tears or ripped off area, then the placement of trephine should be such that these areas are avoided as far as possible in the final graft. However, if there are no peripheral tears, then a well centred trephination should be attempted. It is important to keep the tissue wet throughout the procedure by intermittent use of tissue media.

This technique combines the different lessons that have been learnt over decades by different researchers. It is a simple technique that can be performed with the help of common but often ignored concepts of physics. Firstly, the adhesion between descemet and stroma is apparently more towards the periphery. Therefore, chances of rip off of DM are high in this area. Thus, the use of a trephine size of $9-9.5 \mathrm{~mm}$ may reduce the chances of DM tear while peeling it off. Secondly, the chances of tear are high at the edges of trephinition. When 360 degree edge of DM is made free with the assistance of a sinsky hook the instances of DM tear is reduced markedly (Figure 4) Thirdly, while creating the frill with sinsky hook, it is important to apply a pushing down force at the DM-stroma junction at an angle of 30-45 degree without applying direct force to the DM. Additionally, it is better to re-stain the DM after partial trephinition. This stains the edge of trephinition distinctly and makes it clearly visible, thereby facilitating the step of frill formation and edge lifting. It is much easier to peel after the DM is separated for about 3-4 mm towards the center due to the long arc of force when compared to a shorter arc of force with a $1 \mathrm{~mm}$ frill.

The application of several principles of physics is helpful in better understanding of this technique. We strongly recommend bimanual peeling instead of a single-handed peeling. When a single-handed peeling is done, the force of traction appears at multiple points. While in bimanual peeling the force of traction appears at four points. Additionally, in bimanual peeling, the force is applied over a wider area there is less traction at each point (pressure=force/area assuming that equal force is used). Also, it is important to note that the horizontal vector component of the force neutralizes the traction exerted by each other in bimanual peeling. Lastly, since the peripheral frill has been freed using sinsky, the traction points are primarily located within the central $6 \mathrm{~mm}$ and it has been proven that the adhesive forces are minimal between DM and stroma within this area of the cornea. All these factors, we believe, would reduce the risk of DM tears during DMEK.

We recommend the beginners to go for peeling at a slow speed. As per Newton's rule $\mathrm{F}=\mathrm{ma}$ ( $\mathrm{f}=$ force, $\mathrm{m}=$ mass, $\mathrm{a}=$ acceleration). Assuming that the mass of DM remains constant, the force (or in other words the traction at DM stroma junction) is directly proportional to the acceleration (which is the speed of peeling in our case). Thus, the surgeon must always remember "Go steady, Go slow". Any sudden jerky movement or too fast peeling can lead to excessive traction at the stroma-DM junction with consequent DM tear and hence must be avoided. Keeping a safe margin of around $1.5 \mathrm{~mm}$ (initial trephine 9.5 $\mathrm{mm}$, final trephinition $8 \mathrm{~mm}$ ) allows for exclusion of any torn or ripped off areas of DM at the time of final trephinition.

The adhesion between descemet and stroma is apparently more towards the periphery. The chances of rip off of DM are high in the periphery. Thus, the use of a trephine size of $9-9.5 \mathrm{~mm}$ may reduce the chances of DM tear while peeling it off. The success rate with our technique is around $85-90 \%$.

\section{Outcome}

Griener et al [26] evaluated the outcomes of tissue prepared for Descemet membrane endothelial keratoplasty (DMEK) from diabetic and non-diabetic donors and concluded that Diabetes may be a risk factor for unsuccessful preparation of donor tissue for DMEK so, caution is recommended in these donors. 
The success rate of DMEK tissue preparation with submerged peeling technique has been reported to be $99 \%$ by Tenkman et al. The reason for failure of procedure was presence of spots of strong adhesion between the DM and the stroma leading to multiple horseshoe-shaped tears (HST) in the DM [27].

SCUBA technique by Giebel and Price has been reported to have a failure rate of $4.2 \%$ to $8 \%[28,29]$. Tausif et al. [30] has reported a success rate of $76 \%$ with forceps peeling technique of DMEK graft preparation with no significant difference in the pre and post preparation ECD. The incidence of DM tears and severe cell loss was $10 \%$ and $14 \%$ respectively.

Yoeruek et al. [31] compared the use of 1-point forceps dissection with curvilinear forceps dissection and concluded that the duration of preparation was significantly lower with a lower endothelial cell loss with curvilinear forceps dissection.

A bimanual underwater technique which uses two forceps for better distribution of tension has reported a graft loss rate of only $1 \%$ [32]. Using the same technique, Schlötzer- Schrehardt et al. [33] reported complete peeling in $96 \%$ of corneas with isolated tears in $2 \%$ of grafts.

Parekh et al observed complete detachment rate without any wastage with a novel submerged hydro separation technique. However, the ECL post preservation was observed to be $11.48 \%$ [34].

The success rate of a novel submerged hydro-separation (SubHyS) technique followed by anterior corneal dissection for graft preparation was reported to be $100 \%$ with an average endothelial cell loss of $27.69 \%$ after preservation for 7 days [35].

DMEK donor preparation technique of inverse manual delamination has been compared with combined manual delamination and hydrodissection. The loss of the graft was reported in $25 \%$ by and $4.5 \%$ by technique. However, endothelial damage was low in both the techniques (6 and 5.2\% respectively) [36].

Pneumatic dissection has been reported to be successful by various authors. Venzano et al reported a success rate of $89 \%$ with a low endothelial cell loss (15\%) when the bubble was immediately deflated after DM separation, but high endothelial cell loss (83\%) when the bubble remained inflated [37].

Zarei-Ghanavati et al. reported that pneumatic dissection with reverse big-bubble is more successful in older donors with high endothelial cell counts [19]. While, Busin et al. using a modified approach with performing superficial keratectomy prior to air injection reported a 5\% failure rate with $4 \%$ endothelial cell loss [38]. Later, to add structural support and improve the tissue handling with the pneumatic dissection technique, Studeny et al. described "DMEK with a stromal rim" (DMEK-S) which, had a tissue loss rate of 5\% [39].

The big-bubble technique for DMEK graft preparation has been compared using air and liquid as the medium of separation. Separation using liquid bubble had a greater yield with larger diameter graft and higher maintenance of endothelial cell density and integrity [40].

Also, the site of air injection in pneumatic dissection technique that is central versus peripheral has also been compared. Air injection within the central 8-mm zone was compared with peripheral injection approximately $1 \mathrm{~mm}$ within the limbus. Both the techniques achieved comparable rates of usable tissues with a similar graft diameter. However, peripheral air injection was more likely to yield stroma-free grafts [41].
Brissette et al. [15] has compared the Muraine and SCUBA technique in 40 donor tissues. The median time for graft preparation was noted to be shorter in SCUBA technique along with a significantly higher number of graft tears in Muraine technique. Thus, they concluded that SCUBA technique may be a more effective technique to prepare endothelial donor grafts for DMEK [42].

Endothelial cell loss has also been evaluated using application of a dry ink gentian violet S-stamp to the stromal side of Descemet membrane for confirming the correct orientation of the graft. ECL caused by this S-stamp was found to be $0.6 \%$ (range $0.1 \%-1.0 \%$ ), which is less than one-tenth of the total ECL (13.7\% total ECL, range 9.9\%$17.6 \%$ ) reported in the same technique. (21) A 4-7\% endothelial cell loss rate has been reported using the manual peeling technique [43].

However, a recent study by Mayko et al. [44] did not find any significant change in the ECD before and after DMEK tissue preparation by using two separate analysis methods [44].

\section{References}

1. Melles GRJ, Ong TS, Ververs B, van der Wees J (2006) Descemet membrane endothelial keratoplasty (DMEK). Cornea 25: 987-990. [Crossref]

2. Tong CM, Melles GRJ (2012) Where is endothelial keratoplasty going: from Desceme stripping (automated) endothelial keratoplasty to Descemet membrane endothelial keratoplasty to Descemet membrane endothelial transfer? Can J Ophthalmol J Can Ophtalmol 47: 197-200. [Crossref]

3. Hamzaoglu EC, Straiko MD, Mayko ZM, Sáles CS, Terry MA (2015) The First 100 Eyes of Standardized Descemet Stripping Automated Endothelial Keratoplasty versus Standardized Descemet Membrane Endothelial Keratoplasty. Ophthalmology 122: 2193-2199. [Crossref]

4. Droutsas K, Lazaridis A, Papaconstantinou D, Brouzas D, Moschos MM, et al (2016) Visual Outcomes After Descemet Membrane Endothelial Keratoplasty Versus Descemet Stripping Automated Endothelial Keratoplasty-Comparison of Specific Matched Pairs. Cornea 35: 765-771. [Crossref]

5. Kruse FE, Schrehardt US, Tourtas T (2014) Optimizing outcomes with Descemet's membrane endothelial keratoplasty. Curr Opin Ophthalmol 25: 325-334. [Crossref]

6. Tenkman LR, Price FW, Price MO (2014) Descemet membrane endothelial keratoplasty donor preparation: navigating challenges and improving efficiency. Cornea 33: 319325. [Crossref]

7. Dua HS, Faraj LA, Said DG, Gray T, Lowe J (2013) Human corneal anatomy redefined: a novel pre-Descemet's layer (Dua's layer). Ophthalmology 120: 1778-1785. [Crossref]

8. Price MO, Price FW Jr (2013) Descemet's membrane endothelial keratoplasty surgery: update on the evidence and hurdles to acceptance. Curr Opin Ophthalmol 24: 329-335. [Crossref]

9. Schlotzer-Schrehardt U, Bachmann BO, Laaser K, Cursiefen C, Kruse FE (2011) Characterization of the cleavage plane in DESCemet's membrane endothelial keratoplasty. Ophthalmology 118: 1950-1957. [Crossref]

10. Gorovoy IR, Cui QN, Gorovoy MS (2014) Donor tissue characteristics in preparation of DMEK grafts. Cornea 33: 683-685. [Crossref]

11. Kruse FE, Laaser K, Cursiefen C, Heindl LM, Schlötzer-Schrehardt U, et al. (2011) A stepwise approach to donor preparation and insertion increases safety and outcome of Descemet membrane endothelial keratoplasty. Cornea 30: 580-587. [Crossref]

12. Muraine M, He Z, Toubeau D, Gueudry J, Thuret G, Lefevre S, et al. Validation of a novel device to easy the preparation of endothelial graft for DMEK. Acta Ophthalmol (Copenh). 92

13. Hayashi T, Yuda K, Oyakawa I, Kato N (2017) Use of Brilliant Blue G in Descemet's Membrane Endothelial Keratoplasty. BioMed Res Int.

14. Melles GRJ, Lander F, Rietveld FJR (2002) Transplantation of Descemet's membrane carrying viable endothelium through a small scleral incision. Cornea 21: 415-418. [Crossref]

15. Brissette A, Conlon R, Teichman JC, Yeung S, Ziai S, et al. (2015) Evaluation of a new technique for preparation of endothelial grafts for descemet membrane endothelial keratoplasty. Cornea 34: 557-559. [Crossref] 
16. Schlotzer-Schrehardt U, Bachmann BO, Tourtas T, Cursiefen C, Zenkel M, et al. (2016) Reproducibility of Graft Preparations in Descemet's Membrane Endothelial Keratoplasty. Ophthalmology 120: 1769-1777. [Crossref]

17. Yoeruek, Efdal \& Bartz-Schmidt, Karl-Ulrich (2014) Novel surgical methods in Descemet's membrane endothelial keratoplasty. Expert Review of Ophthalmology 8.

18. Venzano D, Pagani P, Randazzo N, Cabiddu F, Traverso CE (2010) Descemet membrane air-bubble separation in donor corneas. J Cataract Refract Surg 36: 20222027. [Crossref]

19. Zarei-Ghanavati S, Khakshoor H, Zarei-Ghanavati M (2010) Reverse big bubble: a new technique for preparing donor tissue of Descemet membrane endothelial keratoplasty. Br J Ophthalmol 94: 1110-1111. [Crossref]

20. Busin M, Scorcia V, Patel AK, Salvalaio G, Ponzin D (2010) Pneumatic Dissection and Storage of Donor Endothelial Tissue for Descemet's Membrane Endothelial Keratoplasty. Ophthalmology 117: 1517-1520. [Crossref]

21. Veldman PB, Dye PK, Holiman JD, Mayko ZM, Sáles CS, et al. (2015) Stamping an S on DMEK Donor Tissue to Prevent Upside-Down Grafts: Laboratory Validation and Detailed Preparation Technique Description. Cornea 34: 1175-1178. [Crossref]

22. Veldman PB, Dye PK, Holiman JD, Mayko ZM, Sales CS, et al. (2016) The S-stamp in Descemet Membrane Endothelial Keratoplasty Safely Eliminates Upside-down Graft Implantation. Ophthalmology 123: 161-164. [Crossref]

23. Bachmann BO, Laaser K, Cursiefen C, Kruse FE (2010) A method to confirm correct orientation of descemet membrane during descemet membrane endothelial keratoplasty. Am J Ophthalmol 149: 922-925. [Crossref]

24. Bhogal M, Maurino V, Allan BD (2015) Use of a single peripheral triangular mark to ensure correct graft orientation in Descemet membrane endothelial keratoplasty. $J$ Cataract Refract Surg 41: 2022-2024. [Crossref]

25. Akiko Matsuzawa, Takahiko Hayashi, Itaru Oyakawa, Kentaro Yuda, Toshiki Shimizu, et al. (2017) Use of four asymmetric marks to orient the donor graft during Descemet's membrane endothelial keratoplasty. BMJ Open Ophthalmology 1.

26. Greiner MA, Rixen JJ, Wagoner MD, Schmidt GA, Stoeger CG, et al. (2014) Diabetes mellitus increases risk of unsuccessful graft preparation in Descemet membrane endothelial keratoplasty: a multicenter study. Cornea 33: 1129-1133. [Crossref]

27. Tenkman LR, Price FW, Price MO (2014) Descemet membrane endothelial keratoplasty donor preparation: navigating challenges and improving efficiency. Cornea 33: 319325. [Crossref]

28. Price MO, Giebel AW, Fairchild KM, Price FW Jr (2009) Descemet's membrane endothelial keratoplasty: prospective multicenter study of visual and refractive outcomes and endothelial survival. Ophthalmology 116: 2361-2368. [Crossref]

29. Guerra FP, Anshu A, Price MO, Giebel AW, Price FW (2011) Descemet's membrane endothelial keratoplasty: prospective study of 1-year visual outcomes, graft survival, and endothelial cell loss. Ophthalmology 118: 2368-2373. [Crossref]
30. Tausif HN, Johnson L, Titus M, Mavin K, Chandrasekaran N, et al. (2014) Corneal donor tissue preparation for Descemet's membrane endothelial keratoplasty. $J$ Vis Exp JoVE 17: 51919. [Crossref]

31. Yoeruek E, Bartz-Schmidt KU (2013) Novel surgical instruments facilitating Descemet membrane dissection. Cornea 32: 523-526. [Crossref]

32. Kruse FE, Laaser K, Cursiefen C, Heindl LM, Schlötzer-Schrehardt Uet al. (2011) A stepwise approach to donor preparation and insertion increases safety and outcome of Descemet membrane endothelial keratoplasty. Cornea 30: 580-587. [Crossref]

33. Schlotzer-Schrehardt U, Bachmann BO, Tourtas T, Cursiefen C, Zenkel M, et al (2013) Reproducibility of graft preparations in Descemet's membrane endothelial keratoplasty. Ophthalmology 120: 1769-1777. [Crossref]

34. Parekh M, Ruzza A, Salvalaio G, Ferrari S, Camposampiero D, Busin M, et al. (2014) Descemet membrane endothelial keratoplasty tissue preparation from donor corneas using a standardized submerged hydro-separation method. Am J Ophthalmol 158 277-285.e1. [Crossref]

35. Salvalaio G, Parekh M, Ruzza A, Ferrari S, Camposampiero D, et al. (2014) DMEK lenticule preparation from donor corneas using a novel 'SubHyS' technique followed by anterior corneal dissection. Br J Ophthalmol 98: 1120-1125. [Crossref]

36. Rieck PW, Engels T (2017) [A new technique to facilitate donor preparation for DMEK surgery]. Ophthalmologe 114: 728-733. [Crossref]

37. Zarei-Ghanavati S, Khakshoor H, Zarei-Ghanavati M (2010) Reverse big bubble: a new technique for preparing donor tissue of Descemet membrane endothelial keratoplasty. Br J Ophthalmol 94: 1110-1111. [Crossref]

38. Busin M, Scorcia V, Patel AK, Salvalaio G, Ponzin D (2008) Donor tissue preparation for Descemet membrane endothelial keratoplasty. Br J Ophthalmol 95: 1172-1173.

39. Studeny P, Farkas A, Vokrojova M, Liskova P, Jirsova K (2010) Descemet membrane endothelial keratoplasty with a stromal rim (DMEK-S). Br J Ophthalmol 94: 909-914. [Crossref]

40. Ruzza A, Parekh M, Salvalaio G, Ferrari S, Camposampiero D, et al. (2016) Bubble technique for Descemet membrane endothelial keratoplasty tissue preparation in an eye bank: air or liquid? Acta Ophthalmol 93: e129-134. [Crossref]

41. Feizi S, Javadi MA (2016) DMEK lenticule preparation using an air dissection technique: central versus peripheral injection. Eur J Ophthalmol 26: 6-11. [Crossref]

42. Brissette A, Conlon R, Teichman JC, Yeung S, Ziai S, et al. (2015) Evaluation of a new technique for preparation of endothelial grafts for descemet membrane endothelial keratoplasty. Cornea 34: 557-559. [Crossref]

43. Lie JT, Birbal R, Ham L, van der Wees J, Melles GRJ (2008) Donor tissue preparation for Descemet membrane endothelial keratoplasty. J Cataract Refract Surg 34: 15781583. [Crossref]

44. Mayko ZM, Benetz BA, Menegay H, Donovan CP, Stoeger CG, et al. (2016) Donor Endothelial Cell Density Measurements Do Not Change Immediately After DMEK Preparation. Cornea 35: 1556-1561. [Crossref]

Copyright: ( 2019 Maharana PK. This is an open-access article distributed under the terms of the Creative Commons Attribution License, which permits unrestricted use, distribution, and reproduction in any medium, provided the original author and source are credited. 